\title{
Article \\ Development of Microcapsule Bioactive Paper Loaded with Chinese Fir Essential Oil to Improve the Quality of Strawberries
}

\author{
Xiuli Song ${ }^{1}$, Liuxin Shi ${ }^{1, *}$, Su Liu ${ }^{1}$, Chen Hou ${ }^{1}$, Kai Zhu ${ }^{2}$, Qiang Cheng ${ }^{3}{ }^{\mathbb{D}}$ and Luyu Mei ${ }^{1}$ \\ 1 College of Light Industry \& Food Engineering, Nanjing Forestry University, Nanjing 210037, China; \\ songxiuli@njfu.edu.cn (X.S.); liusunjfu@163.com (S.L.); chenhou_369@163.com (C.H.); \\ meiluyu1995@163.com (L.M.) \\ 2 College of Chemical Engineering, Nanjing Forestry University, Nanjing 200137, China; zhukai53@163.com \\ 3 College of Forestry, Nanjing Forestry University, Nanjing 200137, China; chengqiang@njfu.edu.cn \\ * Correspondence: shiliuxin@njfu.edu.cn; Tel.: +86-25-8542-7841
}

check for updates

Citation: Song, X.; Shi, L.; Liu, S.; Hou, C.; Zhu, K.; Cheng, Q.; Mei, L. Development of Microcapsule Bioactive Paper Loaded with Chinese Fir Essential Oil to Improve the Quality of Strawberries. Coatings 2022, 12, 254. https://doi.org/ $10.3390 /$ coatings12020254

Received: 18 January 2022 Accepted: 9 February 2022 Published: 15 February 2022

Publisher's Note: MDPI stays neutral with regard to jurisdictional claims in published maps and institutional affiliations.

Copyright: (C) 2022 by the authors. Licensee MDPI, Basel, Switzerland. This article is an open access article distributed under the terms and conditions of the Creative Commons Attribution (CC BY) license (https:// creativecommons.org/licenses/by/ $4.0 /)$.

\begin{abstract}
Essential oils are natural antibacterial substances and have potential value for application in fruit and vegetable packaging. In this study, Chinese fir essential oil (CFEO) was microencapsulated to prepare food packaging materials for the first time to overcome its volatilization and oxidation shortcomings and to obtain a sustained-release form of the oil. CFEO was effectively encapsulated in gelatin and chitosan using the complex coacervation method, and the encapsulation efficiency, microstructure, infrared spectrum and thermal stability of the microcapsules were evaluated. Experiments confirmed that the microcapsules had some antibacterial activity. A bioactive paper was developed by combining CFEO microcapsules (CFEO-Ms) with paper-based material using the film-forming property of polyvinyl alcohol (PVA). The coated paper showed good mechanical, air permeability and moisture permeability properties. Environmental scanning electron microscopy confirmed that CFEO-Ms bonded well with PVA and was successfully introduced into the paper fiber after coating, forming an obvious coating film on the surface to facilitate the continuous release of CFEO. The shelf life of strawberries was significantly prolonged when the PVA-coated paper mixed with 3\% CFEO-Ms was used for packaging. The results demonstrated that the CFEO-Ms coated paper has the potential to become an effective packaging material for the preservation of strawberries.
\end{abstract}

Keywords: Chinese fir essential oil; microcapsule; coated paper; food packaging; strawberries

\section{Introduction}

Plant essential oils obtained from the flowers, leaves, roots, bark, fruits and seeds of aromatic plants via distillation or physical pressing are highly concentrated extracts that are natural products with environmentally friendly characteristics [1]. Plant essential oils have antibacterial, antimicrobial, anti-insect and antivirus properties and are widely used in fields that include anticorrosion, preservation, medicine, health care and the chemical industry [2,3]. Different types of essential oil have been studied worldwide, including ginger essential oil [4], Angelica essential oil [5], lavender essential oil [6], vetiver essential oil [7], cinnamon essential oil [8] and Chinese fir essential oil [9,10] (CFEO, similar purpose with Tarragon Essential Oil [11,12]), with some results showing that plant essential oils can be used as active substances in packaging materials to prolong food shelf life effectively. Compared with other essential oils, CFEO is derived from wood, which has a pungent woody aroma and lacks fragrance. Most of the research on CFEO has focused on the analysis of the mechanisms underlying its antibacterial activity, but applications are rarely reported. The raw material for CFEO-Chinese fir (Cunninghamia lanceolata) — is an essential commodity in China that is widely used in construction, bridges, shipbuilding, furniture and appliances [13-16]. There is no research on the use of CFEO in food packaging paper, an area for which CFEO has the potential to be used as a natural preservative in packaging materials for food preservation in the future; however, CFEO applications 
have been restricted by its limitations, which include insolubility in water, poor stability, volatilization and oxidation [17]; therefore, there is an urgent need to explore solutions to the above limitations to expand the application of CFEO in food packaging.

Microcapsule technology involves the use of one or more polymer film-forming materials (wall material) to embed a solid, liquid or gas (core material) to form a microsized capsule that protects the core material [18]. Microencapsulation can control the release of volatile substances and can also improve the hydrophilicity of plant essential oils, protect the composition of sensitive core material and mask bad flavors and colors to solve issues in the application of plant essential oils in foodstuffs [19]. Several methods for microcapsule preparation have been proposed, such as spray drying [20], complex coacervation [21], layer self-assembly [22] and Pickering emulsion templates [23]. When oppositely charged polyelectrolytes are present together in a solution, a dense coacervated phase can be formed via electrostatic interaction under appropriate conditions [24]. This process is termed complex coacervation, which has the characteristics of high yield, high efficiency and low influence on the biological activity of the oil-soluble core material under mild conditions $[21,25]$.

As the shell surrounding the core material, the microcapsule wall can effectively protect the release of the core material and improve its stability [26]. Plant essential oil microcapsules are mostly made of natural polymer materials that are biodegradable and biocompatible [27]. Biopolymer systems comprising natural polysaccharides and proteins are the most common combinations for wall materials and provide a safe substrate for food packaging [28]. Gelatin has good solubility, emulsification and gelation, and is one of the most ideal microcapsule wall materials [29]. Chitosan is also widely used as a microcapsule wall material because of its excellent biocompatibility, antibacterial action, biodegradability, safety and wide availability [30].

At present, nondegradable plastic packaging for food poses a threat to environmental safety. Biodegradable polymers with good mechanical properties and low permeability are very important materials in food packaging [31]. Recently, PVA has attracted more and more attention from researchers for biomedical applications such as eye drops, contact lenses, tissue adhesion barriers and artificial cartilage, owing to its unique properties, including biocompatibility, hydrophilicity, nontoxicity and biodegradability. It also has outstanding film-formation characteristics $[32,33]$. Because of this property, coupled with excellent chemical stability and hydrophilicity, it is blended with a variety of synthetic and natural polymers such as a water-soluble film and is used in food packaging [34]. Among biodegradable polymers, polyvinyl alcohol (PVA) has attracted much attention because of its excellent film-forming ability [35]; however, PVA film is also highly hydrophilic and water-soluble, so its application in packaging is limited [36]; therefore, a modified PVA was adopted in this study to improve the water resistance of the packaging material.

In this study, gelatin and chitosan were used as wall materials to prepare CFEO microcapsules (CFEO-Ms) using a complex coacervation method. The encapsulation efficiency, antibacterial activity, particle morphology, thermal stability and infrared spectrum of the microcapsules were evaluated. In addition, PVA was used as a film-forming matrix to prepare paper coated with CFEO-Ms for food packaging. The preservation effect of CFEO-Ms during strawberry storage was evaluated. Taking strawberries as an example for preservation, the effect of CFEO-Ms-coated paper on strawberry preservation is discussed. Compared with other studies, this paper did not study the antibacterial mechanism of $\mathrm{CFEO}$ and the infrared spectrum analysis of the coated paper. Follow-up experiments can be further explored.

\section{Materials and Methods}

\subsection{Materials}

Chitosan (BR, deacetylation degree 80\%-95\%) and gelatin (CP, Type B, Bloom No. 250) were supplied by Sinopharm Chemical Reagent Co., Ltd., Shanghai, China. CFEO was supplied by Anhui Hanfang Biotechnology Co., Ltd., Huangshan, China. Sodium hydroxide 
(AR) was purchased from Nanjing Chemical Reagent Co., Ltd., Nanjing, China. Glacial acetic acid (AR) was obtained from Shanghai Jiuyi Chemical Reagent Co., Ltd., Shanghai, China. Glutaraldehyde (AR) was purchased from Aladdin, Shanghai, China. Staphylococcus aureus (ATCC6538), Escherichia coli (ATCC25922) and Bacillus subtilis (ATCC6633) were obtained from Shanghai Luwei Bio-Technology Co., Ltd., Shanghai, China. Lysogeny broth (LB) was prepared at the Biological Laboratory, Nanjing Forestry University, Nanjing, China. Glycerol (AR, 99\%) and Tween 80 were purchased from Shanghai Macklin Biological Co., Ltd., Shanghai, China. PVA was provided by Anhui Wanwei High-tech Materials Co., Ltd., Chaohu, China

\subsection{Preparation of CFEO-Ms}

CFEO-Ms were prepared via complex coacervation using gelatin and chitosan as wall materials. Typical steps in microencapsulation of essential oil by complex coacervation process involve: (i) emulsification; (ii) electrostatic attraction; (iii) wall formation; (iv) wall hardening [37]. After optimization in preliminary tests, the following preparation method was used. A $0.5 \%$ chitosan solution (Solution A) was prepared by dissolving $0.1 \mathrm{~g}$ of chitosan in $20 \mathrm{~mL}$ of $1 \%$ acetic acid. To prepare Solution B, $1 \mathrm{~g}$ of gelatin was mixed with $200 \mathrm{~mL}$ of distilled water and the mixture was stirred (DF-101S, Shanghai Lichen Bangxi Instrument Technology Company, Shanghai, China) at $50{ }^{\circ} \mathrm{C}$ for $30 \mathrm{~min}$ until all the gelatin was completely dissolved. Then $0.37 \mathrm{~g}$ of CFEO and Tween 80 at a ratio of 2:1 were added to the system. Solution B was emulsified (GBP-USC201L, CSIC715, Hangzhou, China) at $700 \mathrm{~W}$ for $5 \mathrm{~min}$ to create a uniform mixture. Solution A was slowly dispersed into Solution $\mathrm{B}$ via mechanical stirring at $500 \mathrm{rpm}$ at $50{ }^{\circ} \mathrm{C}$ for $30 \mathrm{~min}$. Then the $\mathrm{pH}$ was adjusted to 5.4 with $5 \%$ sodium hydroxide at room temperature and stirring was continued for $1 \mathrm{~h}$. The reaction system was cooled to below $10{ }^{\circ} \mathrm{C}$ in an ice bath, then $0.5 \mathrm{~mL}$ glutaraldehyde was added dropwise over a period of $30 \mathrm{~min}$. A microcapsule suspension was obtained after stirring continuously for $4 \mathrm{~h}$. Finally, the suspension was washed, centrifuged and dried to obtain microcapsule powder.

\subsection{Determination of the CFEO-Ms Encapsulation Efficiency}

A full-wavelength scan of diluted CFEO was performed to determine its maximum absorption wavelength. Different CFEO concentrations $\left(0.01-0.08 \mathrm{mg} \mathrm{L}^{-1}\right)$ were prepared to obtain a standard curve.

Microcapsules $(0.5 \mathrm{~g}$ ) were dissolved in $50 \mathrm{~mL}$ of anhydrous ethanol, soaked for $1 \mathrm{~h}$ and then treated with ultrasound for $30 \mathrm{~min}$. The treated samples were centrifuged at high speed for $10 \mathrm{~min}$ and the absorbance of the supernatant at maximum absorption wavelength (208 nm) was measured. The CFEO-Ms loading capacity was calculated using a standard curve. The encapsulation efficiency was calculated using Equation (1) [38] and the experiment was carried out in triplicate.

$$
\text { Encapsulation efficiency }(\%)=\frac{\text { Total amount of CFEO in microcapsules }}{\text { Iinitial total amount of CFEO }} \times 100
$$

\subsection{Particle Size}

The particle size distribution of microcapsules was determined using a dynamic lightscattering laser particle size analyzer (BT-90, Baxter Instruments Company, Hangzhou, China).

\subsection{Optical Microscopy Observations}

The microcapsule emulsion was diluted several times, one drop was placed on a slide, a cover slip was used to disperse the droplet evenly and the structure was observed under a microscope (Dimension Edge, Bruker, Karlsruhe, Germany). 


\subsection{Thermogravimetric Analysis}

The thermal stability of samples was measured via thermogravimetric analysis (TGA; 209 F1, Netzsch, Selb, Germany). A sample of $8 \mathrm{mg}$ was weighed and put into the TGA furnace. The temperature was increased from 30 to $700{ }^{\circ} \mathrm{C}$ at a constant rate of $20{ }^{\circ} \mathrm{C} / \mathrm{min}$, with nitrogen at a flow rate of $20 \mathrm{~mL} / \mathrm{min}$ as the protective gas.

\subsection{Fourier-Transform Infrared Spectroscopy}

Fourier-transform infrared (FTIR) spectra of chitosan, gelatin, CFEO and chitosangelatin microcapsules were recorded (VERTEX 80 V, Bruker, Ettlingen, Germany). Each sample was scanned 16 times at a resolution of $4 \mathrm{~cm}^{-1}$ in the wave number range from 4000 to $500 \mathrm{~cm}^{-1}$.

\subsection{Antimicrobial Effects of CFEO-Ms}

Staphylococcus aureus (S. aureus), Escherichia coli (E. coli) and Bacillus subtilis (B. subtilis) were selected as test bacteria to explore the antibacterial activity of CFEO-Ms using the agar diffusion method [39]. An aliquot of microcapsule emulsion was centrifuged to half its original volume. Filter paper $(d=6 \mathrm{~mm})$ was soaked in the liquid so that the microcapsule material was evenly distributed on the surface of the filter paper. The filter paper was placed on LB medium $(d=90 \mathrm{~mm})$ mixed with bacterial suspension and agar $\left(55^{\circ} \mathrm{C}\right)$ and incubated at $37^{\circ} \mathrm{C}$ for $24 \mathrm{~h}$. The diameter of the inhibition zone was measured to judge the antibacterial activity of the microcapsule material.

\subsection{Preparation of Coating Solution and Coated Paper}

To prepare the coating solution, $6 \mathrm{~g}$ of PVA powder was added to $100 \mathrm{~mL}$ of distilled water and heated at $90{ }^{\circ} \mathrm{C}$ for $30 \mathrm{~min}$ with stirring. After cooling to room temperature, $2.4 \mathrm{~mL}$ of glycerin was added and stirred at $50{ }^{\circ} \mathrm{C}$ for $30 \mathrm{~min}$ at the same speed to obtain the coating base solution. CFEO-Ms were added to the base solution at different concentrations $(1 \%, 2 \%$ and $3 \%)$ under stirring for $2 \mathrm{~h}$ to evenly distribute the microcapsules in the system and were kept at room temperature for later use. Paper was fixed at one end of the coating roller of a multifunctional coating machine (K303, RK Print Coat Instruments Ltd., Litlington, UK). A certain amount of coating liquid was placed in the coating machine and was evenly applied to the paper. Paper samples coated with PVA/CFEO at microcapsule concentrations of $0 \%, 1 \%, 2 \%$ and $3 \%$ were then dried at $40{ }^{\circ} \mathrm{C}$ for $5 \mathrm{~min}$ in an oven, and are denoted as $\mathrm{P}_{0}, \mathrm{P}_{1 \%}, \mathrm{P}_{2 \%}$ and $\mathrm{P}_{3 \%}$. In addition, uncoated paper was used as a comparison in experiments. To normalize the moisture content of the paper, uncoated paper and coated paper were equilibrated in an environment at constant temperature and humidity.

\subsection{Surface Characterization}

The appearance of microcapsules and coated paper was imaged via environmental scanning electron microscopy (ESEM; Quanta 200, FEI, Hillsboro, OR, USA) and the morphology was observed at acceleration voltages of 2.0 and $15 \mathrm{kV}$, respectively.

\subsection{Physical Properties of Coated Paper}

Grammage was determined as described in the standard method ISO 536, where 10 samples of each paper were cut into size $10 \mathrm{~cm} \times 10 \mathrm{~cm}$ and weighed. The coated paper thickness was measured with a thickness meter (J-DHY03A, Changjiang Paper Instrument Co., Ltd., Sichuan, China) at 10 random locations on each paper in accordance with the ISO 534 , and the average value of the results was taken.

The oxygen resistance of coated paper was evaluated by measuring the oxygen permeability (VAC-V1, Jinan Blu-ray Electromechanical Co., Ltd., Jinan, China) of samples at $30 \pm 2{ }^{\circ} \mathrm{C}$ and $60 \%$ relative humidity (RH). The upper and lower cavities of the instrument were degassed for $10 \mathrm{~h}$ and samples were tested after the upper chamber pressure stabilized. The average value for three parallel samples was used as the final result. 
The influence of the microcapsule concentration on the water vapor transmittance of coated paper was investigated. The water vapor permeability (WVP) of paper coated with different microcapsule concentrations was measured using a gas permeability tester at $38^{\circ} \mathrm{C}$ and 70\% RH (W3/060, Jinan Blu-ray Electromechanical Co., Ltd.). The sample was tested for $15 \mathrm{~min}$ in triplicate and the average of the three tests was used as the result.

\subsection{Mechanical Properties of Coated Paper}

Samples were equilibrated at constant temperature and humidity for 2 days. A paper flexural tester (YQ-Z-31, Changchun Yueming Small Experimental Machine Co., Ltd., Changchun, China) and paper tension instrument (WZL-300, Hangzhou Light Tong Instrument Development Co., Ltd., Hangzhou, China) were used to evaluate the mechanical properties of samples from each experimental group. Experiments were carried out at $23{ }^{\circ} \mathrm{C}$ and $50 \% \mathrm{RH}$ under controlled conditions. Rectangular samples $(15 \mathrm{~mm} \times 100 \mathrm{~mm})$ were cut from each type of paper for testing. Experiments were performed 10 times for each group and the average value was taken.

\subsection{Quality Parameters of Strawberries}

\subsubsection{Weight Loss}

The weight loss for strawberries during storage was determined using the difference method. Strawberries were weighed on the initial and sampling days and the following Formula (2) [40] was used to calculate the weight loss:

$$
\text { Weight loss }(\%)=\frac{m_{0}-m_{1}}{m_{0}} \times 100
$$

where $m_{0}$ is the initial weight of the strawberries and $m_{1}$ is the weight on the sampling day.

\subsubsection{Decay Percentage}

Twenty strawberries were randomly selected from each group and the surface decay of strawberries was observed on the sampling day. The Formula (3) [41] for calculating the decay percentage is as follows:

$$
\text { Percentage decay }(\%)=\frac{n_{r}}{n_{0}} \times 100
$$

where $n_{r}$ is the number of decayed strawberries and $n_{0}$ is the total number of strawberries.

\subsubsection{Firmness}

Strawberry firmness was measured using a GY-2 fruit hardness tester (Suzhou Qile Electronic Technology Co., Ltd., Suzhou, China). Before measurement, approximately $1 \mathrm{~cm}^{2}$ of the epidermis on the surface of a strawberry was peeled off. During measurements, the cylindrical probe $(\varphi=3.50 \pm 0.02 \mathrm{~mm})$ at the bottom of the hardness tester was placed perpendicular to the surface of the strawberry and evenly pressed into the fruit until it stopped at $10 \mathrm{~mm}$ on the scale line. The average of the three measurements was taken as the firmness result.

\subsubsection{Soluble Solids Content}

The soluble solids content (SSC) of strawberry was determined using a refractometer (JHGXL/T-32ATC, Chzhou Jiuhua Optical Instrument Co., Ltd., Guangzhou, China). Strawberry juice was dropped on the detection prism, the cover plate was closed (making sure that there were no residual bubbles) and the instrument was aligned with the light source for reading. The scale value on the dividing line indicates the concentration of the solution. 


\subsection{Statistical Analysis}

All statistical analyses were conducted using Origin software (version: OriginPro 2021b (64-bit) SR2 9.8.5.21, IBM, Chicago, IL, USA) and results are expressed as the mean \pm standard deviation. One-factor analysis of variance was used to compare the different treatments. The Duncan test was used to determine the significance of differences between groups at a significance level of $p<0.05$.

\section{Results and Discussion}

\subsection{Characterization of Chitosan-Gelatin Microcapsules}

\subsubsection{UV Standard Curve for CFEO}

A UV spectrophotometer (Tu-1900, AOE Instruments, Shanghai, China) was used to measure the absorbance of different CFEO concentrations at $208 \mathrm{~nm}$. The standard curve obtained is shown in Figure 1. It was evident that the CFEO concentration was linearly correlated with the peak area at $208 \mathrm{~nm}$ according to $\mathrm{y}=11.051 \mathrm{x}+0.0623$, with $\mathrm{R}^{2}=0.9995$.

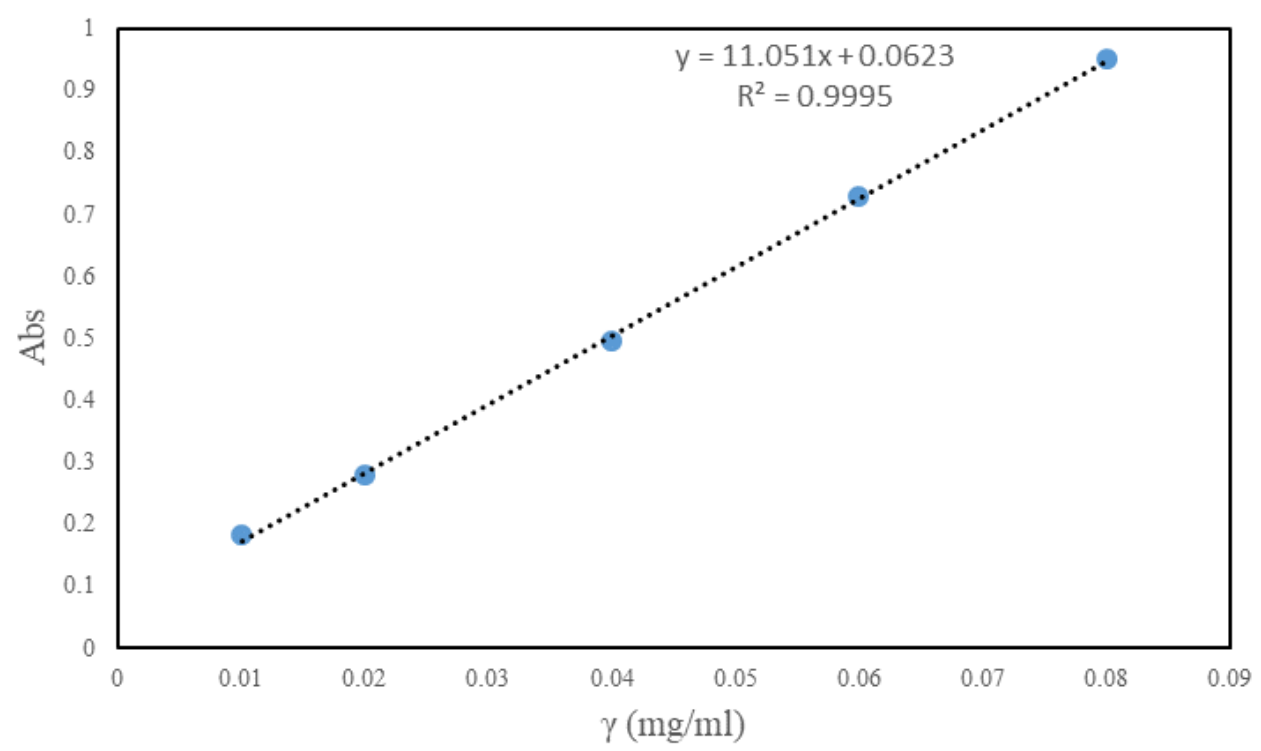

Figure 1. UV standard curve for CFEO.

\subsubsection{Particle Size Distribution of the Microcapsules}

The particle size distribution of CFEO-Ms prepared via complex coacervation is shown in Figure 2. It was evident that the microcapsule particle size was in the range $111-250 \mathrm{~nm}$ and exhibited a normal distribution.

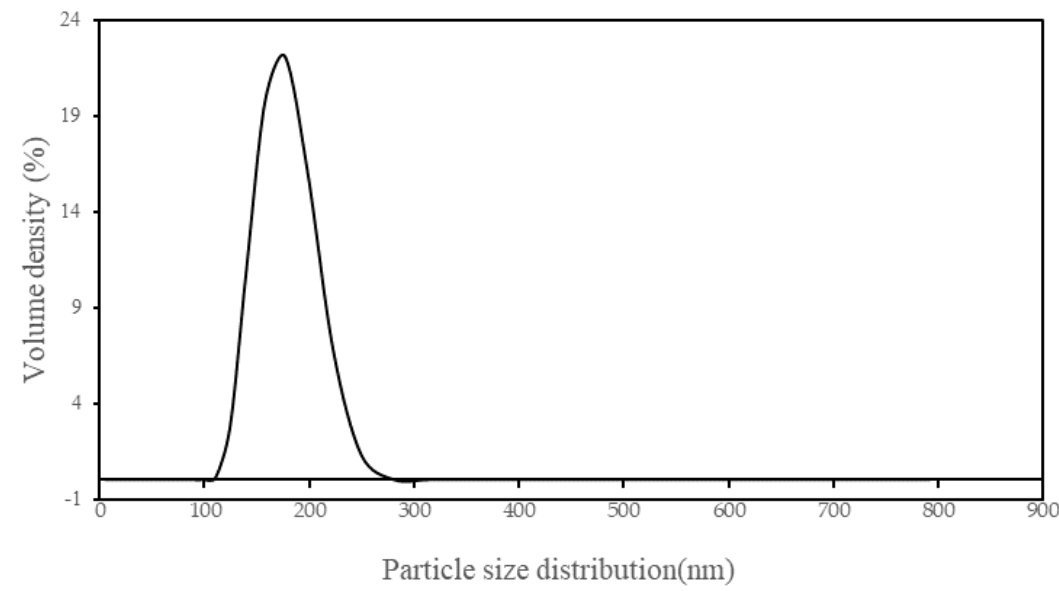

Figure 2. Particle size distribution of the CFEO-Ms. 


\subsubsection{Morphology}

Figure 3 shows a microscopy image of CFEO-Ms. Most of the microcapsules in the image were clustered, which maybe because of the low dilution ratio and poor dispersion. It was apparent from the small number of particles of large size that the microcapsules prepared had a multinuclear structure and thick capsule wall, which can better control the release of the core CFEO and play a role in its sustained release.
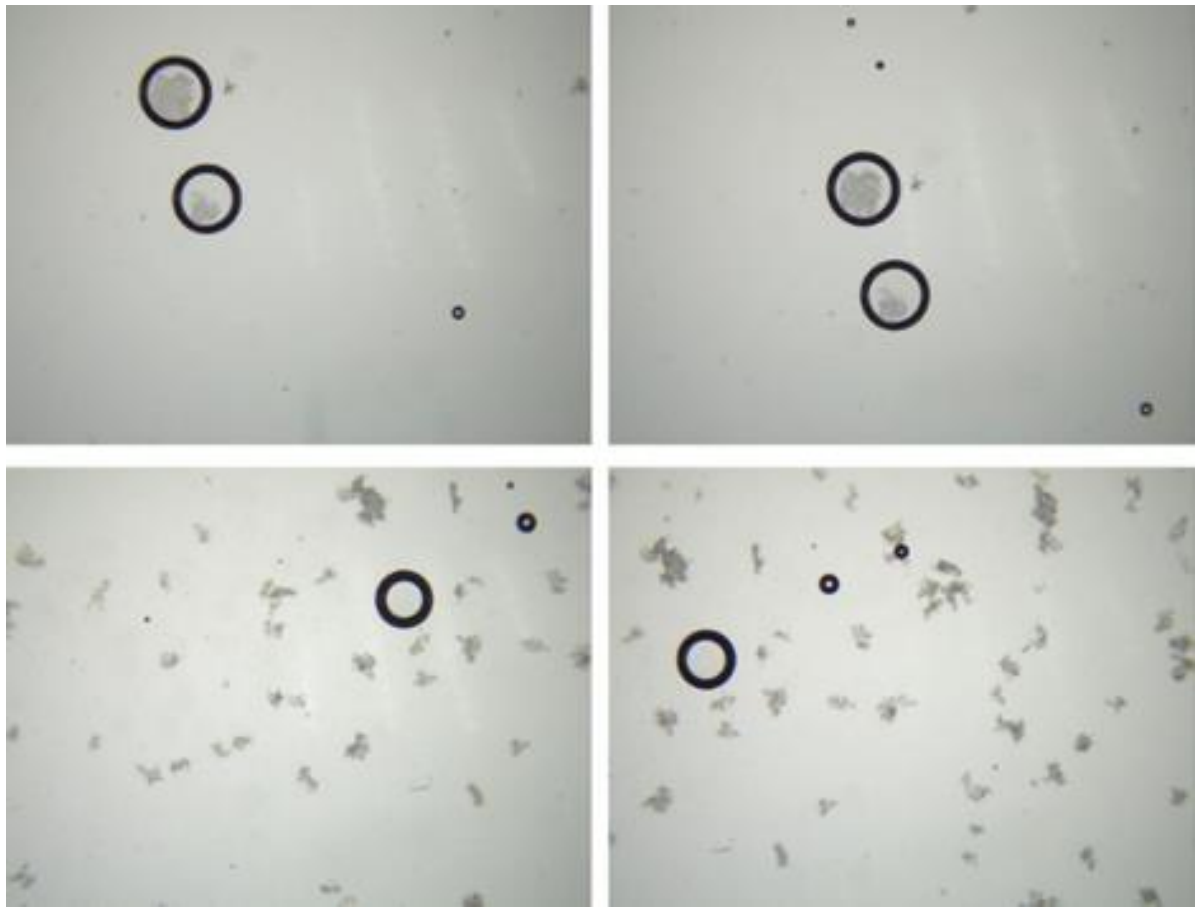

Figure 3. Micrographs of the CFEO-Ms

\subsubsection{Microcapsule Structure Analysis}

The surface structure of the CFEO-Ms is shown in Figure 4. The microcapsules had a spherical surface morphology. This was because glutaraldehyde can react with nitrogen atoms on the amide and amine groups of gelatin and chitosan to form covalent bonds [42], thus enhancing the gel network of the capsule material. Meanwhile, covalent cross-linking reduced the swelling of microcapsules dispersed in distilled water. In addition, crosslinking protected the integrity of the capsule wall during freeze-drying, thus maintaining the integrity of cross-linked microcapsules [43].

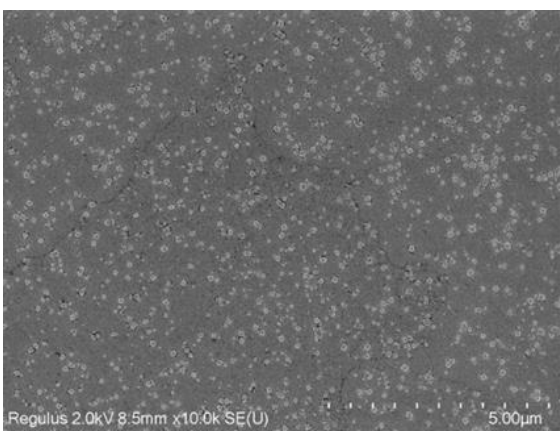

(a)

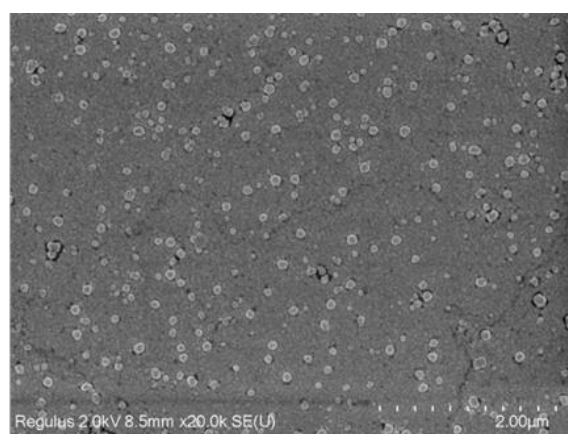

(b)

Figure 4. ESEM images of CFEO-Ms at magnification of (a) $10,000 \times$ and (b) $20,000 \times$. 


\subsubsection{Thermal Stability}

TGA is an important measure for evaluating the thermal stability of materials. Figure 5 shows TGA and derivative thermogravimetric (DTG) curves for microcapsules, CFEO, chitosan and gelatin. The temperature at which initial weight loss occurred for the microcapsules was about $100{ }^{\circ} \mathrm{C}$, which may be attributable to the loss of residual water in the microcapsules [44]. At this temperature, CFEO also began to decompose up to approximately $179^{\circ} \mathrm{C}$, with a high weight loss of $98.72 \%$, indicating that the core material was volatile. Another weight-loss event ( $50 \%)$ was observed for the microcapsules between 250 and $400{ }^{\circ} \mathrm{C}$. This may be related to self-degradation because of the instability of the microcapsules in this range: as the temperature rises, the covalent bonds formed via electrostatic attraction between gelatin and chitosan are destroyed and the core material is constantly released [45]. It has been reported that gelatin decomposes at $275-375{ }^{\circ} \mathrm{C}$ and that the wall material also decomposes gradually [46]. During the final TGA stage $\left(400-600{ }^{\circ} \mathrm{C}\right)$, the weight loss from the microcapsules was approximately $15 \%$. In this temperature range, the core material had been completely released and the weight loss can be attributed to the decomposition of the wall material; therefore, the results indicated that CFEO was successfully encapsulated in the wall material and that the microcapsule structure improved the stability of the core material at high temperature.

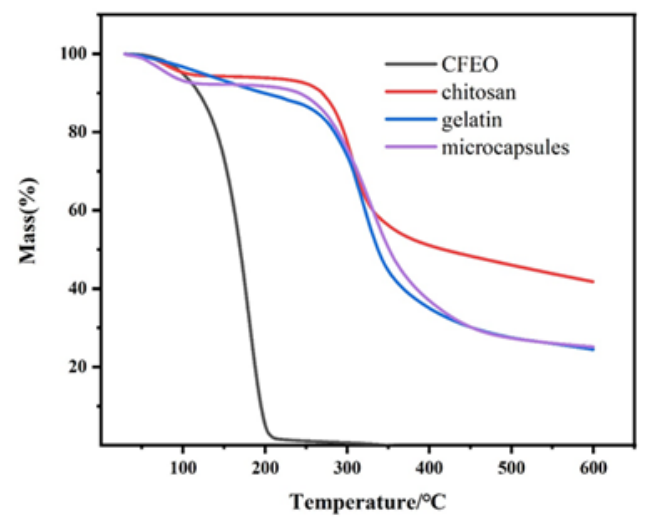

(a)

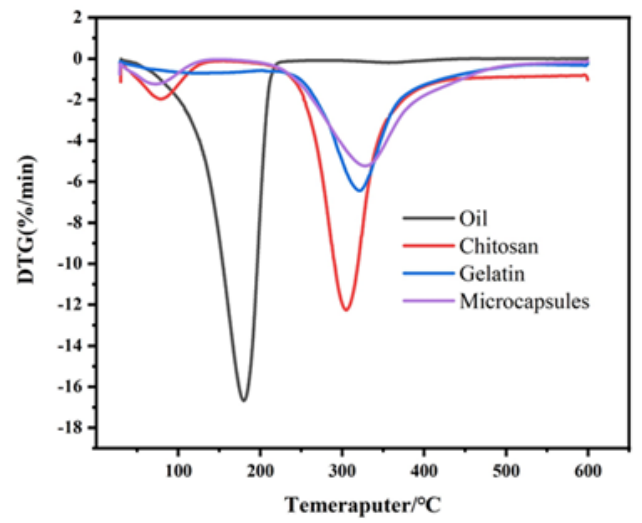

(b)

Figure 5. TGA (a) and DTG (b) curves for CFEO, chitosan, gelatin and CFEO microcapsules.

\subsubsection{FTIR Analysis}

FTIR is the main technique used to determine the molecular structure of proteins, polysaccharides and drugs [47]. Thus, FTIR analysis was used to confirm the compatibility of gelatin and chitosan for microencapsulation in terms of intermolecular interactions between $-\mathrm{NH}_{2}$ and $-\mathrm{COO}-$ groups. Figure 6 shows FTIR spectra for CFEO, chitosan, gelatin and CFEO-Ms. The characteristic absorption peaks for gelatin can be attributed to amino $\mathrm{N}-\mathrm{H}$ stretching vibrations $\left(3426 \mathrm{~cm}^{-1}\right)$, alkyl C-H stretching vibrations $\left(2930 \mathrm{~cm}^{-1}\right), \mathrm{C}-\mathrm{N}$ stretching vibrations for atoms in the amide bond $\left(1243 \mathrm{~cm}^{-1}\right)$ and amide carbonyl $\mathrm{C}=\mathrm{O}$ stretching vibrations $\left(1635 \mathrm{~cm}^{-1}\right)$. The characteristic peaks for chitosan were at $3430 \mathrm{~cm}^{-1}$, $2947 \mathrm{~cm}^{-1}$ and $1648 \mathrm{~cm}^{-1}$, corresponding to $-\mathrm{OH}$ and $-\mathrm{NH}_{2}$ stretching vibrations, $\mathrm{C}-\mathrm{H}$ stretching vibration and characteristic amide absorption, respectively. The hydroxyl $(-\mathrm{OH})$, amine $\left(-\mathrm{NH}_{2}\right)$ and carboxylate (-COO-) groups in gelatin could form hydrogen bonds with $-\mathrm{OH}$ and ammonium $\left(-\mathrm{NH}^{3+}\right)$ in chitosan [48]. In the FTIR spectrum for CFEO, peaks at $2934 \mathrm{~cm}^{-1}$ and $2869 \mathrm{~cm}^{-1}$ can be attributed to $-\mathrm{CH}_{2}$ stretching vibrations, while the peaks at $1450 \mathrm{~cm}^{-1}$ and $1372 \mathrm{~cm}^{-1}$ are due to $-\mathrm{CH}_{3}$ stretching vibrations. It is known that the main component of CFEO is cedrene. The peaks for CFEO at $1640 \mathrm{~cm}^{-1}$ and $884 \mathrm{~cm}^{-1}$ can be assigned to $\mathrm{C}=\mathrm{C}$ stretching vibrations and $=\mathrm{CH}$ bending vibrations, respectively. The FTIR spectrum for CFEO-Ms contained characteristic CFEO absorption peaks, from which it can be hypothesized that CFEO contained within the microcapsules retained its chemical structure; however, the absorption peaks were significantly weaker. This was 
because infrared vibration peaks for CFEO were limited and intermolecular forces were weakened after microencapsulation, so the results confirmed that CFEO was successfully encapsulated by the wall material.

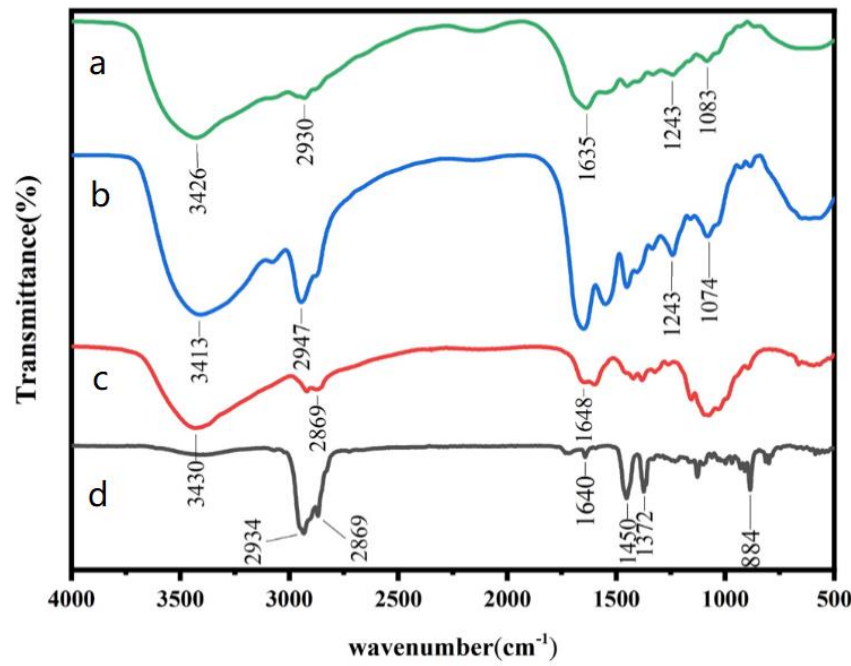

Figure 6. FTIR spectra: $\mathrm{a}=$ gelatin; $\mathrm{b}=\mathrm{CFEO}$ microcapsules; $\mathrm{c}=$ chitosan; $\mathrm{d}=\mathrm{CFEO}$.

\subsubsection{Antimicrobial Activity}

The antibacterial effects of CFEO-Ms on E. coli, S. aureus and B. subtilis are shown in Figure 7. It was evident that CFEO-Ms had a significant antibacterial effect on the three species. The average diameter of the antibacterial zone was 12.1, 11.8 and $10.9 \mathrm{~mm}$, respectively, with no significant difference between the bacteria. Mei et al. [49] results show that Gram-positive bacteria are more sensitive to CFEO than Gram-negative bacteria. The difference in results may be related to the essential oil composition. Relevant studies $[10,50]$ show that the main components of CFEO differ according to the extraction method and the tree parts used. The main components of the CFEO used in this study were cedarwood and $\alpha$-cedrene. A synergistic effect between them may contribute to the CFEO antibacterial activity to some extent. Further study is needed to elucidate the mechanism underlying the antibacterial effect.

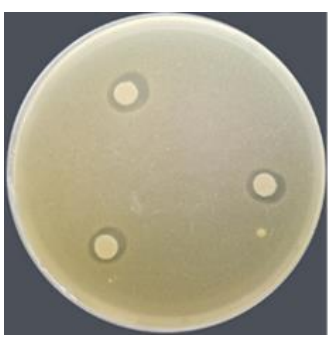

E. coli

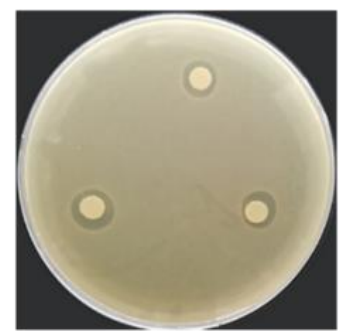

S. aureus

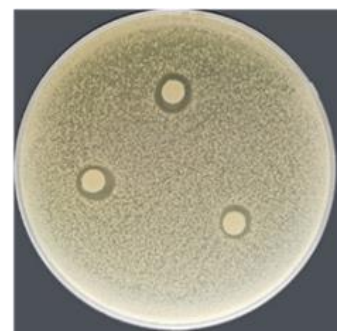

B. subtilis

Figure 7. Antibacterial effect of CFEO-M on E. coli, S. aureus and B. subtilis.

\subsection{Characterization of Coated Paper}

\subsubsection{Surface Morphology}

The effect of coating on paper morphology was observed using ESEM. Figure 8 shows ESEM images of uncoated paper and the four coated papers $\left(\mathrm{P}_{0}, \mathrm{P}_{1 \%}, \mathrm{P}_{2 \%}\right.$ and $\left.\mathrm{P}_{3 \%}\right)$. It was apparent that the uncoated paper had a porous network structure with an irregular arrangement of fibers. After coating with the PVA base solution $\left(\mathrm{P}_{0}\right)$, the paper surface was covered with PVA evenly distributed on the fibers, forming a dense film structure. According to results for oxygen permeability and WVP, the coated paper had good barrier properties. For the coating solutions containing CFEO-Ms, as the CFEO-Ms concentration 
increased, microcapsule agglomeration occurred on the paper surface (Figure 8d,e) and PVA film formation weakened. This was consistent with the permeability results in Table 1.
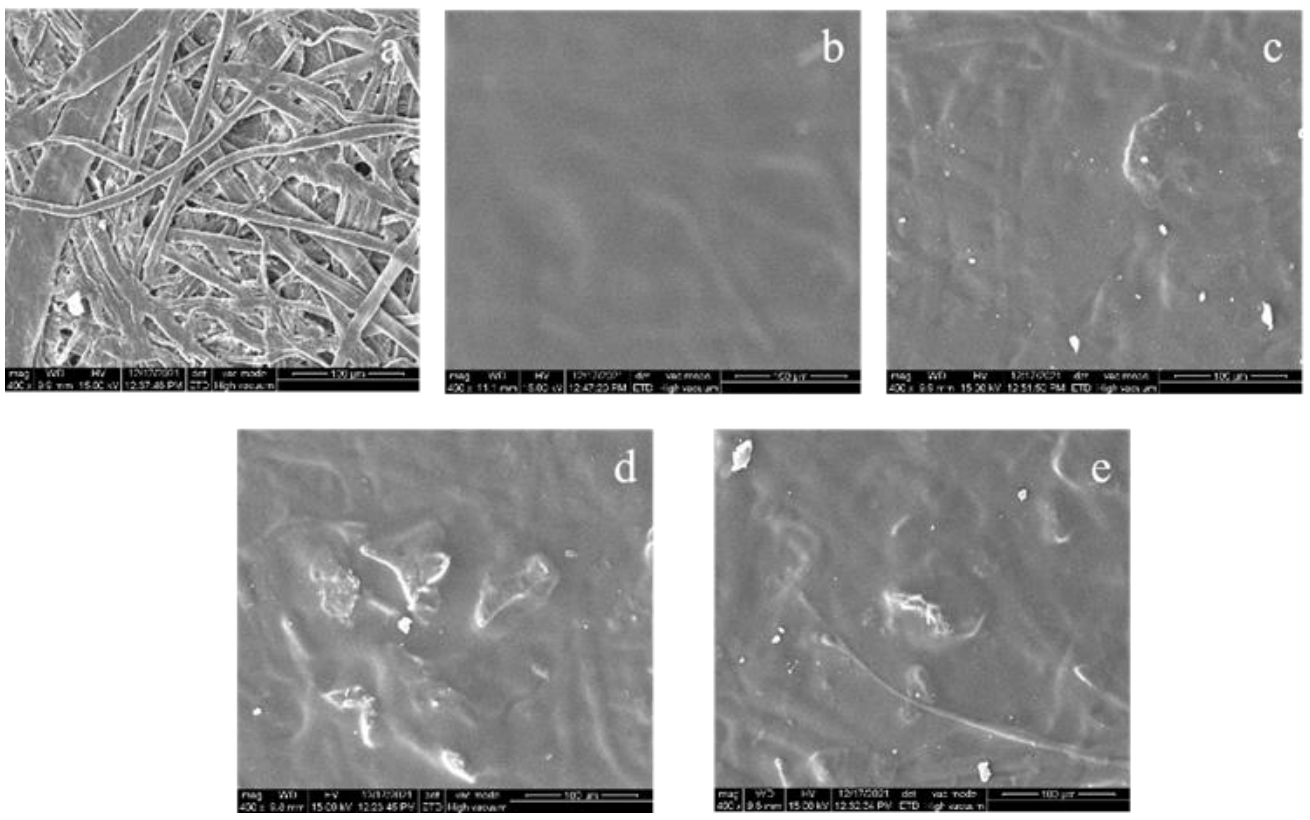

Figure 8. Scanning electron micrographs of (a) uncoated paper, (b) $\mathrm{P}_{0},(\mathbf{c}) \mathrm{P}_{1 \%},(\mathbf{d}) \mathrm{P}_{2} \%$ and (e) $\mathrm{P}_{3 \%}$ at $400 \times$ magnification.

Table 1. Weight, thickness, OTR and WVP of uncoated and coated paper.

\begin{tabular}{|c|c|c|c|c|}
\hline Sample & $\begin{array}{l}\text { Grammage } \\
\left(\mathrm{g} \mathrm{m}^{-2}\right)\end{array}$ & $\begin{array}{l}\text { Thickness } \\
(\mu \mathrm{m})\end{array}$ & $\begin{array}{c}\text { OTR } \\
\left(\mathrm{cm}^{3} \mathrm{~m}^{-2} \mathrm{day}^{-1}\right. \\
\left.0.1^{-1} \mathrm{MPa}^{-1}\right)\end{array}$ & $\begin{array}{c}\text { WVP } \\
\left(\mathrm{g} \mathrm{m}^{-2} \mathrm{day}^{-1}\right)\end{array}$ \\
\hline Uncoated & $45.0 \pm 0.13^{c}$ & $60.6 \pm 0.5^{d}$ & - & - \\
\hline $\mathrm{P}_{0}$ & $56.4 \pm 0.16^{c}$ & $69.7 \pm 0.6^{d}$ & $30.97 \pm 2.18^{b}$ & $1029.69 \pm 12.37^{d}$ \\
\hline $\mathrm{P}_{1 \%}$ & $57.6 \pm 0.20^{a}$ & $90.0 \pm 1.1^{c}$ & $1.82 \pm 0.25^{c}$ & $890.14 \pm 22.10^{a}$ \\
\hline $\mathrm{P}_{2 \%}$ & $59.5 \pm 0.17^{b}$ & $94.3 \pm 2.5^{b}$ & $4.76 \pm 0.23^{c}$ & $1026.32 \pm 16.59^{c}$ \\
\hline $\mathrm{P}_{3 \%}$ & $61.4 \pm 0.22^{\mathrm{a}}$ & $107.2 \pm 2.6^{a}$ & $96.25 \pm 8.1^{\mathrm{a}}$ & $926.66 \pm 18.25^{b}$ \\
\hline
\end{tabular}

"- indicates that the permeability was below the test limit of the in
column indicate a significant difference between samples $(p<0.05)$.

\subsubsection{Physical Properties}

Table 1 lists results for the grammage, thickness and permeability of uncoated, PVAcoated and PVA-CFEO-Ms (PVA-Ms)-coated papers. The grammage and thickness of the base paper were $45 \mathrm{~g} / \mathrm{m}^{2}$ and $60.6 \mu \mathrm{m}$, respectively. The grammage and thickness of the coated papers increased uniformly on the addition of increasing CFEO-Ms concentrations to the coating solution, which confirmed the effectiveness of the coating formation [51].

The oxygen permeability is the volume of oxygen passing through a unit area of the sample in $24 \mathrm{~h}$ under a pressure difference of $0.1 \mathrm{Mpa}$ [52]. It can be seen from Table 1 that the oxygen permeability of coated papers first decreased and then increased with increasing CFEO-Ms concentration. When the CFEO-Ms concentration was increased from 0 to $1 \mathrm{~g} / 100 \mathrm{~mL}$, the permeability decreased from 30.97 to $1.82 \mathrm{~cm}^{3} \mathrm{~m}^{-2} \mathrm{~d}^{-1} 0.1^{-1} \mathrm{Mpa}^{-1}$, a decrease of $94.12 \%$. When the CFEO-Ms concentration was increased to $3 \mathrm{~g} / 100 \mathrm{~mL}$, the oxygen permeability reached $96.25 \mathrm{~cm}^{3} \mathrm{~m}^{-2} \mathrm{~d}^{-1} 0.1^{-1} \mathrm{Mpa}^{-1}$, an increase of $67.82 \%$. The reason may be that the thickness of the CFEO-Ms layer on the coated paper surface increased with the concentration in the coating solution, which would extend the diffusion path for gas molecules in the film [53]. The surface structure of the paper confirmed this. Figure 8 shows that the surface of the uncoated paper is porous and the surface of PVA-coated paper is smooth. The addition of microcapsules and PVA forms a denser film covering the surface of P1\% coated paper. At the same time, if a small number of microcapsules were added, 
these could combine with the PVA film matrix to form a denser microcapsule film, so that the coated paper would have a better barrier effect; however, excessive CFEO-Ms addition may lead to agglomeration of microcapsules in the PVA matrix, resulting in poor bonding in the interface between the two phases and thus facilitating the diffusion of gas molecules in the film matrix and a significant increase in oxygen permeability.

WVP is the ability of water to penetrate and pass through a material [54]. Water plays an important role in fruit quality and stability [55]. Permeability results for uncoated paper, CFEO-Ms-coated paper and PVA-coated paper are shown in Table 1. The permeability of uncoated paper exceeded the measurement range of the instrument. Overall, WVP was lower for the PVA-Ms paper than for paper coated without CFEO-Ms. This may be because CFEO-Ms addition changed the network structure during film formation and more hydroxyl groups were cross-linked, leading to a decrease in the density of the film structure [56]. At the same time, the tortuosity of the water vapor diffusion path increased on CFEO-Ms addition. Moreover, the free space volume of the system increases as the CFEO-Ms concentration increases and the paper surface will become loose and porous, so the permeability will also increase.

\subsubsection{Mechanical Properties}

The influence of CFEO-Ms addition on the mechanical properties of coated paper was investigated in terms of the folding strength and tensile strength. Folding strength is the capability that paper resists repeated folding, while tensile strength is the tension that paper can withstand $[57,58]$. Considering the anisotropy of paper, two measurement directions (machine direction and cross-machine direction) were used. In general, the longitudinal mechanical properties of paper are greater than its transverse mechanical properties [59]. It was evident from Figure 9a that the folding strength in the vertical and horizontal directions conforms to this observation. In comparison to the uncoated paper, the folding strength of coated paper was significantly affected by the coating layer and its folding strength was also significantly improved. As the CFEO-Ms concentration was increased, the folding strength of the coated paper also increased, indicating that CFEO-Ms addition improved the affinity between the PVA and the paper fibers. The greater the CFEO-Ms concentration, the stronger was the adhesion between the fibers and PVA, increasing the folding strength of the paper.

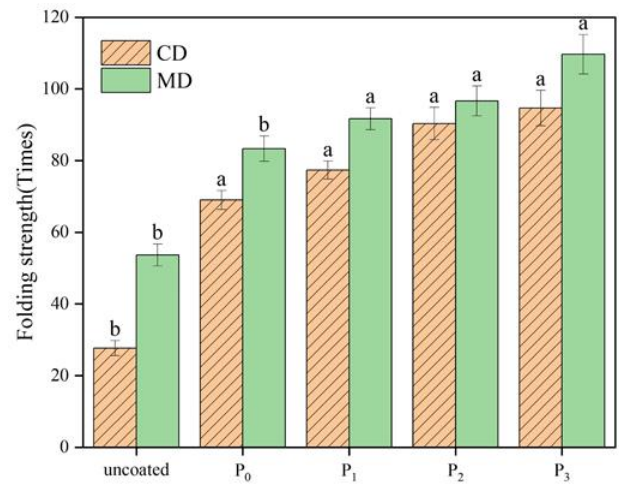

(a)

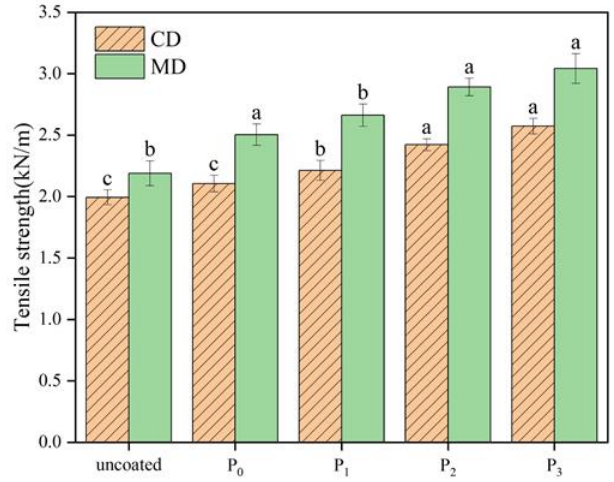

(b)

Figure 9. Folding strength (a) and tensile strength (b) of uncoated paper, PVA-coated paper and paper coated with PVA-CFEO-Ms at different concentrations. Data are expressed as the mean \pm standard deviation $(n=3)$. Different letters on the diagram indicate significant differences between groups at $p<0.05$. $\mathrm{CD}=$ machine direction; $\mathrm{MD}=$ cross-machine direction.

Figure $9 \mathrm{~b}$ shows tensile strength results for the different samples. According to the overall trend, CFEO-Ms addition improved the tensile strength of coated paper, regardless of the measurement direction. The reason may be that infiltration of the coating liquid into paper fibers and spaces between fibers enhanced the binding force between fibers [60]. 
Second, CFEO-Ms were evenly dispersed in the PVA film matrix, leading to an orderly arrangement of PVA molecules [61]. Moreover, the large specific surface area for CFEO-Ms promoted the binding of the microcapsules to the PVA film [62].

\subsubsection{Weight Loss}

Strawberries have a high water content and water loss during storage can cause wrinkles [63]. The weight loss of strawberry is an important index that reflects respiration rate and moisture evaporation between the fruit tissue and surrounding air. As shown in Figure 10a, the weight loss of strawberries increased with the storage time. After 7 days of storage, strawberry weight in the control, $\mathrm{P}_{0}$ and $\mathrm{P}_{3} \%$ groups decreased by $45.31 \%, 39.43 \%$ and $24.31 \%$, respectively. The data trend suggested that coated paper played an important role as a water barrier between the strawberries and the environment during storage. Moreover, the presence of CFEO-Ms in PVA-coated paper inhibited microorganism growth on the strawberry surface, reduced the respiration rate of the fruit and better-retained water within the strawberries, resulting in a lower rate of weight loss [64].
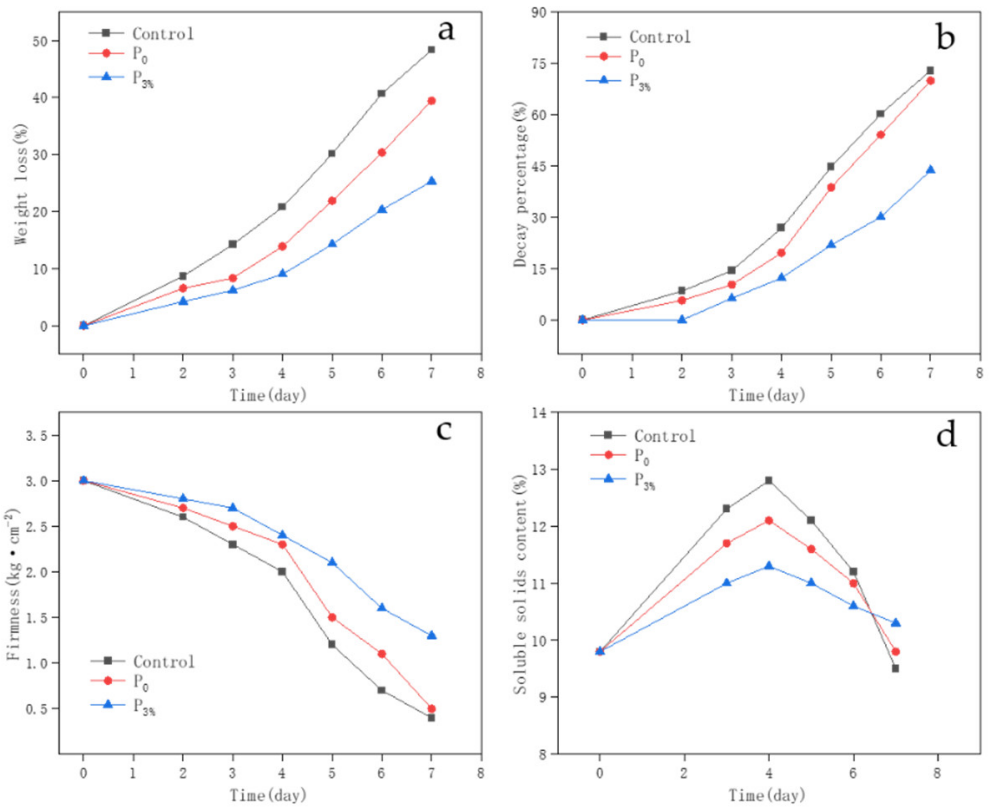

Figure 10. Effects of coated and uncoated paper on percentage decay (a), weight loss (b), firmness (c) and soluble solids content (d) during strawberry storage at room temperature.

\subsubsection{Percentage Decay}

Because of physiological changes, environmental effects and harmful microbial infection, the surface of strawberries gradually softens and decays during storage [65]. Figure 10b shows that on day 2 of storage, fruits in the control and $P_{0}$ groups showed varying degrees of decay, while those in group $\mathrm{P}_{3} \%$ were well preserved. On day 4 , rotting in the control group intensified and the fruit had no edible value. After storage for 7 days, the percentage decay was $72.85 \%$ for the control group, $69.9 \%$ for the $\mathrm{P}_{0}$ group and $43.7 \%$ for the $\mathrm{P}_{3 \%}$ group. The data showed that CFEO had a preservation effect on strawberries and prolonged their edible date. This may be due to the slow release of CFEO from the microcapsules, which then inhibited the growth of some microorganisms on the strawberry surface. This result was consistent with the appearance of the fruit during storage in Figure 11. These findings suggested that PVA-Ms paper could keep the weight loss of strawberries within a certain range. 


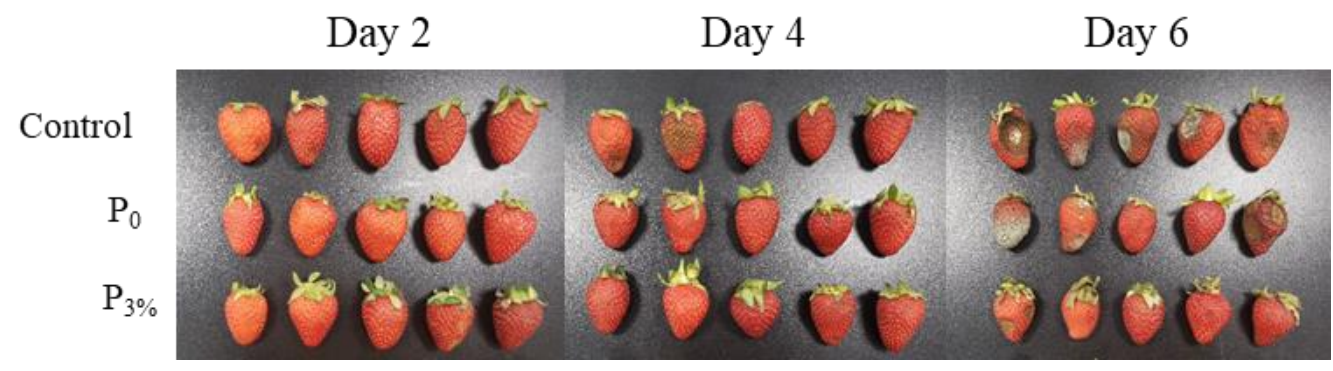

Figure 11. Appearance of strawberries coated with different treatment groups.

\subsubsection{Firmness}

Fruit firmness plays a significant role in consumer decision-making [66]. As the berries ripen, the flesh gradually softens. As a result, firmness and storability are reduced, which is related to the degradation of fruit pectin and cellular matter [54,67]. Changes in strawberry firmness during storage are shown in Figure 10c. Over the whole storage period, the firmness of strawberries covered with PVA-Ms paper decreased slowly, confirming paper $\mathrm{P}_{3 \%}$ was more effective in maintaining the firmness of the fruit, which was attributed to its better barrier property and mechanical properties that retarded the metabolic activity and water loss of the strawberry [68], and slow down the texture degradation [69]. After 7 days of storage, strawberry firmness was significantly higher than for the control and $\mathrm{P}_{0}$ groups. The firmness of the $\mathrm{P}_{0}$ group decreased significantly on day 4 , indicating acceleration of the decomposition rate of pectin by pectinase, and the endurance of the strawberry epidermis and fiber tissue under pressure decreased, further indicating that CFEO-Ms could reduce the degradation rate for strawberry cell materials and minimize water losses.

\subsubsection{Soluble Solids Content}

The soluble solids in strawberries are a measure of their total sugar content, indicating the degree of ripening and directly affecting the fruit flavor and the degree of consumer acceptance [70,71]. The influence of uncoated and coated papers on strawberry SSC is shown in Figure 10d. It was evident that SSC for the three strawberry samples (control, $\mathrm{P}_{0}$ and $\mathrm{P}_{3 \%}$ ) increased gradually with metabolism from day 1 to day 4 , indicating that sucrose synthesis occurred in the strawberries during this period [72]. In the later period, SSC decreased with sugar metabolism, especially in the control and $\mathrm{P}_{0}$ groups, which may be because of a faster strawberry respiratory rate in these two groups and the need for more sucrose hydrolysis to maintain physiological activity, resulting in more SSC depletion. Strawberries in the $\mathrm{P}_{3 \%}$ group showed the most stable trend over the whole storage period. On day 7 of storage, SSC was $9.5 \%, 9.8 \%$ and $10.4 \%$ for the control, $\mathrm{P}_{0}$ and $\mathrm{P}_{3 \%}$ groups, respectively. The data showed that $\mathrm{P}_{3 \%}$ paper resulted in a higher SSC level at the end of the storage period, which may be because CFEO-Ms-coated paper can slow the metabolism and respiration rate of strawberries to some extent.

\section{Conclusions}

CFEO-Ms were prepared with gelatin and chitosan as wall materials to encapsulate CFEO and the encapsulation efficiency of microcapsules was 72.24\%. ESEM and FTIR results confirmed strong bonding between the two wall compounds. TGA showed that the synthesized microcapsules had good stability. Bacteriostatic experiments demonstrated that the microcapsules had strong antibacterial activity against three species. The combination of CFEO-Ms and PVA enhanced the mechanical properties of the paper and reduced its oxygen permeability and WVP, and the PVA-Ms paper was suitable for packaging fresh strawberries. In comparison to the control group, the firmness, weight and SSC of strawberries covered with $\mathrm{P}_{3} \%$ were well maintained. The results demonstrated that CFEO-Ms could be used as a natural antibacterial agent to produce coated paper for strawberry packaging materials, inhibit the respiration rate of strawberry and the breeding of microorganisms on the surface, and prolong the shelf life of strawberry. In future 
research, the physical and chemical properties of the coated paper will be further explored to evaluate the feasibility of food preservation.

Author Contributions: Conceptualization, X.S. and L.S.; Investigation, X.S.; Writing—original draft, X.S.; Project administration, K.Z.; Resources, Q.C.; Supervision, L.S.; Data curation, L.M., S.L. and C.H. All authors have read and agreed to the published version of the manuscript.

Funding: This research was funded by the cinnamon oil raw material forest cultivation and aroma oil deep processing technology integration and demonstration project (2018YFD0600405), Jiangsu CoInnovation Center for Efficient Processing and Utilization of Forest Resources, Nanjing Forestry University.

Institutional Review Board Statement: "Not applicable" for studies not involving humans or animals. Informed Consent Statement: “Not applicable" for studies not involving humans.

Data Availability Statement: The data presented in this study are available in the article.

Conflicts of Interest: The authors declare no conflict of interest.

\section{References}

1. Pavlić, B.; Teslić, N.; Zengin, G.; Đurović, S.; Rakić, D.; Cvetanović, A.; Gunes, A.; Zeković, Z. Antioxidant and enzyme-inhibitory activity of peppermint extracts and essential oils obtained by conventional and emerging extraction techniques. Food Chem. 2021, 338, 127724. [CrossRef]

2. Esmaeili, Y.; Paidari, S.; Baghbaderani, S.A.; Nateghi, L.; Al-Hassan, A.A.; Ariffin, F. Essential oils as natural antimicrobial agents in postharvest treatments of fruits and vegetables: A review. J. Food Meas. Charact. 2021, 16, 507-522. [CrossRef]

3. Semeniuc, C.A.; Socaciu, M.-I.; Socaci, S.A.; Mureșan, V.; Nagy, M.; Rotar, A.M. Chemometric Comparison and Classification of Some Essential Oils Extracted from Plants Belonging to Apiaceae and Lamiaceae Families Based on Their Chemical Composition and Biological Activities. Molecules 2018, 23, 2261. [CrossRef]

4. Lee, Y.R.; Shin, H.S. Effectiveness of Ginger Essential Oil on Postoperative Nausea and Vomiting in Abdominal Surgery Patients. J. Altern. Complement. Med. 2017, 23, 196-200. [CrossRef]

5. Tabanca, N.; Gao, Z.; Demirci, B.; Techen, N.; Wedge, D.E.; Ali, A.; Sampson, B.J.; Werle, C.; Bernier, U.R.; Khan, I.A.; et al Molecular and Phytochemical Investigation of Angelica dahurica and Angelica pubescentis Essential Oils and Their Biological Activity against Aedes aegypti, Stephanitis pyrioides, and Colletotrichum Species. J. Agric. Food Chem. 2014, 62, 8848-8857. [CrossRef]

6. Ahmady, S.; Rezaei, M.; Khatony, A. Comparing effects of aromatherapy with lavender essential oil and orange essential oil on fatigue of hemodialysis patients: A randomized trial. Complement. Ther. Clin. Pract. 2019, 36, 64-68. [CrossRef]

7. Gautam, M.; Agrawal, M. Application potential of Chrysopogon zizanioides (L.) Roberty for the remediation of red mud-treated soil: An analysis via determining alterations in essential oil content and composition. Int. J. Phytorem. 2021, 23, 1356-1364. [CrossRef] [PubMed]

8. Tu, Q.-B.; Wang, P.-Y.; Sheng, S.; Xu, Y.; Wang, J.-Z.; You, S.; Zhu, A.-H.; Wang, J.; Wu, F.-A. Microencapsulation and Antimicrobial Activity of Plant Essential Oil Against Ralstonia solanacearum. Waste Biomass-Valorization 2020, 11, 5273-5282. [CrossRef]

9. Zhang, X.; Zhang, Z.-F.; Ma, Q.-Z.; Deng, H.-P.; Zhang, M.-L. Study on Utilization Value of Pure Natural Medical Resources of Benzene/Ethanol Extractives of Chinese Fir Wood. In Proceedings of the 2009 Symposium on Photonics and Optoelectronics, Wuhan, China, 14-16 August 2009.

10. Hsu, K.-P.; Su, Y.-C.; Ho, C.-L. Chemical Compositions and In Vitro Antiphytopathogenic Fungi Activities of the Leaf and Cones Essential Oils of Cunninghamia lanceolate from Taiwan. Nat. Prod. Commun. 2020, 15, 15. [CrossRef]

11. Socaciu, M.-I.; Fogarasi, M.; Simon, E.; Semeniuc, C.; Socaci, S.; Podar, A.; Vodnar, D. Effects of Whey Protein Isolate-Based Film Incorporated with Tarragon Essential Oil on the Quality and Shelf-Life of Refrigerated Brook Trout. Foods 2021, 10, 401. [CrossRef] [PubMed]

12. Socaciu, M.-I.; Fogarasi, M.; Semeniuc, C.A.; Socaci, S.A.; Rotar, M.A.; Mureşan, V.; Pop, O.L.; Vodnar, D.C. Formulation and Characterization of Antimicrobial Edible Films Based on Whey Protein Isolate and Tarragon Essential Oil. Polymers 2020, 12, 1748. [CrossRef] [PubMed]

13. Xu, J.; Lie, G.; Xue, L. Effects of gap size on diversity of soil fauna in a Cunninghamia lanceolata stand damaged by an ice storm in southern China. J. For. Res. 2016, 27, 1427-1434. [CrossRef]

14. Yan, X.; Wang, L.; Qian, X. Effect of Coating Process on Performance of Reversible Thermochromic Waterborne Coatings for Chinese Fir. Coatings 2020, 10, 223. [CrossRef]

15. Cao, S.; Hu, R.; Wu, X.; Sun, Y.; Wu, B.; Duan, H.; Lin, H.; Wu, M.; Fang, L.; Yu, X.; et al. Two chemical mutagens modulate the seed germination, growth, and phenotypic characteristics of Chinese fir (Cunninghamia lanceolata). J. For. Res. 2021, 32, 2077-2085. [CrossRef]

16. Li, Y.; Chen, J.; Yang, Y.; Li, C.; Peng, W. Chemical compositions and functions of Chinese fir volatiles. Therm. Sci. 2020, 24, 1853-1859. [CrossRef] 
17. Rao, J.; Chen, B.; McClements, D.J. Improving the Efficacy of Essential Oils as Antimicrobials in Foods: Mechanisms of Action. Annu. Rev. Food Sci. Technol. 2019, 10, 365-387. [CrossRef] [PubMed]

18. Weitbrecht, K.; Schwab, S.; Rupp, C.; Bieler, E.; Dürrenberger, M.; Bleyer, G.; Schumacher, S.; Kassemeyer, H.-H.; Fuchs, R.; Schlücker, E. Microencapsulation-An innovative technique to improve the fungicide efficacy of copper against grapevine downy mildew. Crop Prot. 2021, 139, 105382. [CrossRef]

19. Ju, J.; Xie, Y.; Guo, Y.; Cheng, Y.; Qian, H.; Yao, W. Application of starch microcapsules containing essential oil in food preservation. Crit. Rev. Food Sci. Nutr. 2018, 60, 2825-2836. [CrossRef]

20. Parthasarathi, S.; Anandharamakrishnan, C. Enhancement of oral bioavailability of vitamin E by spray-freeze drying of whey protein microcapsules. Food Bioprod. Process. 2016, 100, 469-476. [CrossRef]

21. Muhoza, B.; Xia, S.; Wang, X.; Zhang, X.; Li, Y.; Zhang, S. Microencapsulation of essential oils by complex coacervation method: Preparation, thermal stability, release properties and applications. Crit. Rev. Food Sci. Nutr. 2020, 1363-1382. [CrossRef]

22. Zhang, Z.; Zhang, S.; Su, R.; Xiong, D.; Feng, W.; Chen, J. Controlled Release Mechanism and Antibacterial Effect of Layer-By-Layer Self-Assembly Thyme Oil Microcapsule. J. Food Sci. 2019, 84, 1427-1438. [CrossRef] [PubMed]

23. Zhang, Z.; Cheng, M.; Gabriel, M.S.; Neto Ângela, A.T.; Bernardes, J.D.S.; Berry, R.; Tam, K.C. Polymeric hollow microcapsules (PHM) via cellulose nanocrystal stabilized Pickering emulsion polymerization. J. Colloid Interface Sci. 2019, 555, 489-497. [CrossRef] [PubMed]

24. Huang, G.-Q.; Wang, H.-O.; Wang, F.-W.; Du, Y.-L.; Xiao, J.-X. Maillard reaction in protein-Polysaccharide coacervated microcapsules and its effects on microcapsule properties. Int. J. Biol. Macromol. 2020, 155, 1194-1201. [CrossRef] [PubMed]

25. Gouin, S. Microencapsulation: Industrial appraisal of existing technologies and trends. Trends Food Sci. Technol. 2004, 15, 330-347. [CrossRef]

26. Veiga, R.D.S.D.; Da Silva-Buzanello, R.A.; Corso, M.P.; Canan, C. Essential oils microencapsulated obtained by spray drying: A review. J. Essent. Oil Res. 2019, 31, 457-473. [CrossRef]

27. Botrel, D.A.; Vilela Borges, S.; Victória de Barros Fernandes, R.; Dantas Viana, A.; Maria Gomes da Costa, J.; Reginaldo Marques, G. Evaluation of spray drying conditions on properties of microencapsulated oregano essential oil. Int. J. Food Sci. Technol. 2012, 47, 2289-2296. [CrossRef]

28. Qiang, L.; Li-Jian, S.; Xian-Feng, G.; Yang, W.; Xue-Ling, Z. Simultaneous Optimization of Multiple Response Variables for the Gelatin-chitosan Microcapsules Containing Angelica Essential Oil. Iran. J. Pharm. Res. 2017, 16, 50-62.

29. Man, L. Preparation and quality evaluation of microcapsules of volatile oil from Ledum palustre. Zhongyaocai 2014, 37, 675-678.

30. Sargın, I.; Kaya, M.; Arslan, G.; Baran, T.; Ceter, T. Preparation and characterisation of biodegradable pollen-chitosan microcapsules and its application in heavy metal removal. Bioresour. Technol. 2015, 177, 1-7. [CrossRef]

31. Bui, V.K.H.; Park, D.; Nguyen, M.K.; Moon, J.-Y.; Lee, Y.-C. Preparation of Antimicrobial Aminoclays/Poly(vinyl alcohol) Nanocomposite Hydrogel Films by Freeze-Thawing Method. Macromol. Res. 2019, 27, 523-525. [CrossRef]

32. Yang, S.B.; Yoo, S.H.; Lee, J.S.; Kim, J.W.; Yeum, J.H. Surface Properties of a Novel Poly(vinyl alcohol) Film Prepared by Heterogeneous Saponification of Poly(vinyl acetate) Film. Polymers 2017, 9, 493. [CrossRef]

33. Chen, J.; Li, Y.; Zhang, Y.; Zhu, Y. Preparation and characterization of graphene oxide reinforced PVA film with boric acid as crosslinker. J. Appl. Polym. Sci. 2015, 132, 42000. [CrossRef]

34. Yu, Z.; Li, B.; Chu, J.; Zhang, P. Silica in situ enhanced PVA/chitosan biodegradable films for food packages. Carbohydr. Polym. 2018, 184, 214-220. [CrossRef] [PubMed]

35. Chen, X.; Taguchi, T. Enhanced Skin Adhesive Property of Hydrophobically Modified Poly(vinyl alcohol) Films. ACS Omega 2020 5, 1519-1527. [CrossRef] [PubMed]

36. Tripathi, S.; Mehrotra, G.; Dutta, P. Physicochemical and bioactivity of cross-linked chitosan-PVA film for food packaging applications. Int. J. Biol. Macromol. 2009, 45, 372-376. [CrossRef]

37. Huang, H.; Huang, C.; Yin, C.; Khan, M.R.U.; Zhao, H.; Xu, Y.; Huang, L.; Zheng, D.; Qi, M. Preparation and characterization of $\beta$-cyclodextrin-oregano essential oil microcapsule and its effect on storage behavior of purple yam. J. Sci. Food Agric. 2020, 100, 4849-4857. [CrossRef]

38. Çil, G.I.; Küplülü, Ö.; Cengiz, G.; Korkmaz, S.D.; Arslan, B.; Gürcan, S. Antibacterial activity of Turkish honey against selected foodborne pathogens. Ank. Üniversitesi Vet. Fakültesi Derg. 2020, 67, 413-418. [CrossRef]

39. Roy, J.C.; Giraud, S.; Ferri, A.; Mossotti, R.; Guan, J.; Salaün, F. Influence of process parameters on microcapsule formation from chitosan-Type B gelatin complex coacervates. Carbohydr. Polym. 2018, 198, 281-293. [CrossRef]

40. Piacentini, E.; Giorno, L.; Dragosavac, M.M.; Vladisavljevic, G.T.; Holdich, R.G. Microencapsulation of oil droplets using cold water fish gelatine/gum arabic complex coacervation by membrane emulsification. Food Res. Int. 2013, 53, 362-372. [CrossRef]

41. Ang, L.F.; Darwis, Y.; Yee, L.; Yam, M.F. Microencapsulation Curcuminoids for Effective Delivery in Pharmaceutical Application. Pharmaceutics 2019, 11, 451. [CrossRef]

42. Lee, A.R.; Han, C.H.; Yi, E. Preparation and characterization of melamine-formaldehyde microcapsules containing Citrus unshiu essential oil. Fibers Polym. 2014, 15, 35-40. [CrossRef]

43. Liu, J.; Liu, C.; Liu, Y.; Chen, M.; Hu, Y.; Yang, Z. Study on the grafting of chitosan-gelatin microcapsules onto cotton fabrics and its antibacterial effect. Colloids Surf. B Biointerfaces 2013, 109, 103-108. [CrossRef] [PubMed]

44. Nunes, C.N.; Emond, J.-P.; Fla State Hort, S. Relationship between Weight Loss and Visual Quality of Fruits and Vegetables. In Proceedings of the Annual Meeting of the Florida-State-Horticultural-Society, Palm Beach Gardens, FL, USA, 3-5 June 2007. 
45. Unal, H.; Akbudak, B. Some quality properties of three sweet cherry (Prunus avium L.) Cultivars during shelf life. Ital. J. Food Sci. 2008, 20, 391-399.

46. Duhoranimana, E.; Karangwa, E.; Lai, L.; Xu, X.; Yu, J.; Xia, S.; Zhang, X.; Muhoza, B.; Habinshuti, I. Effect of sodium carboxymethyl cellulose on complex coacervates formation with gelatin: Coacervates characterization, stabilization and formation mechanism. Food Hydrocoll. 2017, 69, 111-120. [CrossRef]

47. Tiernan, H.; Byrne, B.; Kazarian, S.G. ATR-FTIR spectroscopy and spectroscopic imaging for the analysis of biopharmaceuticals. Spectrochim. Acta Part A Mol. Biomol. Spectrosc. 2020, 241, 118636. [CrossRef] [PubMed]

48. Staroszczyk, H.; Sztuka, K.; Wolska, J.; Wojtasz-Pajak, A.; Kołodziejska, I. Interactions of fish gelatin and chitosan in uncrosslinked and crosslinked with EDC films: FT-IR study. Spectrochim. Acta Part A Mol. Biomol. Spectrosc. 2014, 117, 707-712. [CrossRef]

49. Mei, L.; Shi, L.; Song, X.; Liu, S.; Cheng, Q.; Zhu, K.; Zhuge, R. Characterization of Carboxymethyl Cellulose Films Incorporated with Chinese Fir Essential Oil and Their Application to Quality Improvement of Shine Muscat Grape. Coatings 2021, 11, 97. [CrossRef]

50. Wang, J.; Li, J.; Li, S.; Freitag, C.; Morrell, J.J. Antifungal activities of Cunninghamia lanceolata heartwood extractives. Bioresources 2011, 6, 606-614. [CrossRef]

51. Battisti, R.; Fronza, N.; Júnior Álvaro, V.; da Silveira, S.M.; Damas, M.S.P.; Quadri, M.G.N. Gelatin-coated paper with antimicrobial and antioxidant effect for beef packaging. Food Packag. Shelf Life 2017, 11, 115-124. [CrossRef]

52. Mikkonen, K.S.; Heikkilä, M.I.; Helén, H.; Hyvönen, L.; Tenkanen, M. Spruce galactoglucomannan films show promising barrier properties. Carbohydr. Polym. 2010, 79, 1107-1112. [CrossRef]

53. Kim, T.Y.; Song, E.H.; Kang, B.H.; Kim, S.J.; Lee, Y.-H.; Ju, B.-K. Hydrolyzed hexagonal boron nitride/polymer nanocomposites for transparent gas barrier film. Nanotechnology 2017, 28, 12LT01. [CrossRef] [PubMed]

54. Shao, P.; Yu, J.; Chen, H.; Gao, H. Development of microcapsule bioactive paper loaded with cinnamon essential oil to improve the quality of edible fungi. Food Packag. Shelf Life 2021, 27, 100617. [CrossRef]

55. Cai, C.; Ma, R.; Duan, M.; Deng, Y.; Liu, T.; Lu, D. Effect of starch film containing thyme essential oil microcapsules on physicochemical activity of mango. LWT-Food Sci. Technol. 2020, 131, 109700. [CrossRef]

56. Yoon, S.-D.; Chough, S.-H.; Park, H.-R. Effects of additives with different functional groups on the physical properties of starch/PVA blend film. J. Appl. Polym. Sci. 2006, 100, 3733-3740. [CrossRef]

57. Brodnjak, U.V. Experimental investigation of novel curdlan/chitosan coatings on packaging paper. Prog. Org. Coatings 2017, 112, 86-92. [CrossRef]

58. Hassan, M.L.; Fadel, S.M.; Hassan, E.A. Acrylate/Nanofibrillated Cellulose Nanocomposites and Their Use for Paper Coating. J. Nanomater. 2018, 2018, 4953834. [CrossRef]

59. Morsy, F.A.; El-Sherbiny, S. Mechanical properties of coated paper: Influence of coating properties and pigment Blends. J. Mater. Sci. 2004, 39, 7327-7332. [CrossRef]

60. Masni-Azian, A.; Choudhury, I.A.; Sihombing, H.; Yuhazri, M.Y. Tensile Properties Evaluation of Paper Pulp Packaging at Different Sections and Orientations on the Egg Tray. In Proceedings of the International Conference on Advanced Materials Engineering and Technology (ICAMET 2012), Penang, Malaysia, 28-30 November 2012. [CrossRef]

61. Lu, H.; Zhang, L.; Shi, Y.; Ma, J.; Zhou, X. Fabrication of Composite Ultrafiltration Membrane by Coating Urea Formaldehyde Resin on Filter Paper. Coatings 2020, 10, 482. [CrossRef]

62. Storeck, A.; Batz-Sohn, C. Novel inkjet coating alumina. In Proceedings of the 2nd International Conference on Digital Fabrication Technologies, Denver, CO, USA, 17-22 September 2006.

63. Jiang, Y.; Yu, L.; Hu, Y.; Zhu, Z.; Zhuang, C.; Zhao, Y.; Zhong, Y. The preservation performance of chitosan coating with different molecular weight on strawberry using electrostatic spraying technique. Int. J. Biol. Macromol. 2020, 151, 278-285. [CrossRef]

64. Jongsri, P.; Wangsomboondee, T.; Rojsitthisak, P.; Seraypheap, K. Effect of molecular weights of chitosan coating on postharvest quality and physicochemical characteristics of mango fruit. LWT 2016, 73, 28-36. [CrossRef]

65. Wszelaki, A. Effect of combinations of hot water dips, biological control and controlled atmospheres for control of gray mold on harvested strawberries. Postharvest Biol. Technol. 2003, 27, 255-264. [CrossRef]

66. Shu, Z.J.; Liu, S.Q.; Yuan, Y.; Xia, Y.B. Quality Evaluation of Strawberries Packed with Perforated Film. In Proceedings of the International Conference on Packaging Technology and Science (ICPTS 2012), Chinese Soc Vibrat Engn, Comm Packag Dynam, Ningbo, China, 25-28 October 2012. [CrossRef]

67. Ahmed, L.; Martin-Diana, A.B.; Rico, D.; Barry-Ryan, C. The impact of delactosed whey permeate treatment on shelf-life and antioxidant contents of strawberries. Int. J. Food Sci. Technol. 2012, 47, 1430-1438. [CrossRef]

68. He, Y.; Bose, S.K.; Wang, W.; Jia, X.; Lu, H.; Yin, H. Pre-Harvest Treatment of Chitosan Oligosaccharides Improved Strawberry Fruit Quality. Int. J. Mol. Sci. 2018, 19, 2194. [CrossRef] [PubMed]

69. Petriccione, M.; Mastrobuoni, F.; Pasquariello, M.S.; Zampella, L.; Nobis, E.; Capriolo, G.; Scortichini, M. Effect of Chitosan Coating on the Postharvest Quality and Antioxidant Enzyme System Response of Strawberry Fruit during Cold Storage. Foods 2015, 4, 501-523. [CrossRef]

70. Aday, M.S.; Caner, C. The shelf life extension of fresh strawberries using an oxygen absorber in the biobased package. LWT 2013, 52, 102-109. [CrossRef] 
71. Wang, Y.; Zhang, J.; Cui, W.; Guan, C.; Mao, W.; Zhang, Z. Improvement in Fruit Quality by Overexpressing miR399a in Woodland Strawberry. J. Agric. Food Chem. 2017, 65, 7361-7370. [CrossRef] [PubMed]

72. Hazarika, T.K.; Lalrinfeli; Lalthanmuani; Lalchhanmawia, J.; Mandal, D. Alteration of quality attributes and shelf-life in strawberry (Fragaria $\times$ ananassa) fruits during storage as influenced by edible coatings. Indian J. Agric. Sci. 2019, 89, $28-34$. 